\title{
The Effects of Balneotherapy on Oxidant/Antioxidant Status in Patients With Fibromyalgia: An Observational Study
}

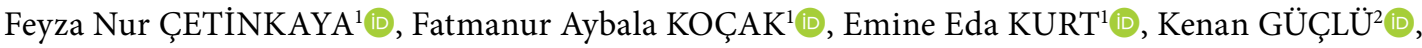

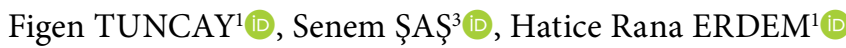

\begin{abstract}
${ }^{1}$ Department of Physical Medicine and Rehabilitation, Kırşehir Ahi Evran University Faculty of Medicine, Kırşehir, Turkey
${ }^{2}$ Department of Medical Biochemistry, Kırşehir Ahi Evran University Training and Research Hospital, Kırşehir, Turkey ${ }^{3}$ Department of Physical Medicine and Rehabilitation, Kırşehir Ahi Evran University Training and Research Hospital, Kırşehir, Turkey
\end{abstract}

\begin{abstract}
Objectives: This study aims to evaluate whether there was a difference between oxidative stress index (OSI), total antioxidant status (TAS), and total oxidant status (TOS) values between patients with fibromyalgia syndrome (FMS) and healthy controls, and to show the effect of balneotherapy on clinical conditions such as pain, depression, and quality of life in patients with FMS and oxidative stress.

Patients and methods: Thirty-five females (mean age 39.9 \pm 5.8 years; range, 18 to 50 years) with fibromyalgia and 35 healthy females (mean age $37.9 \pm 6.6$ years; range, 18 to 50 years) were included in the study. The TAS, TOS, and OSI of patients with FMS and healthy controls were measured. Disease severity was evaluated using the Fibromyalgia Impact Questionnaire, pain levels were evaluated using a visual analog scale (VAS), mood was evaluated using the Beck Depression Inventory (BDI), and quality of life was evaluated using the Short Form 36 (SF-36). Patients with FMS were given 15 sessions of balneotherapy. After treatment, the laboratory and clinical parameters of the patients were reevaluated.

Results: Although the TAS levels of patients with FMS were not significantly different from those of the control group ( $p=0.114)$, the TOS and OSI levels were higher than those of the control group $(p<0.001)$. The VAS, BDI, and SF-36 parameter scores of patients with FMS were significantly higher than those of the control group $(p<0.001)$. A statistically significant decrease $(p<0.001)$ in TOS and OSI levels of patients with FMS was detected after balneotherapy; however, the TAS levels of patients with FMS did not change significantly $(p=0.538)$. All clinical parameters showed significant improvement with balneotherapy $(p<0.001)$.
\end{abstract}

Conclusion: An oxidative disorder was detected in patients with FMS compared with the control group. Balneotherapy showed antioxidant activity and decreased oxidative stress while also improving clinical parameters and quality of life.

Keywords: Balneotherapy, fibromyalgia, oxidative stress, pain, quality of life.

Fibromyalgia syndrome (FMS) is a chronic syndrome accompanied by somatic-cognitive symptoms such as chronic widespread pain, tenderness, sleep disturbance, and fatigue. The etiopathogenesis of FMS is still unknown, but genetic, environmental, biochemical factors; neuroendocrine disorders; and autonomic, peripheral and central nervous system disorders, sleep disorders, immunologic, and psychological factors are thought to play a role. ${ }^{1}$ Oxidative stress, which has been shown to play an important role in the pathogenesis of many diseases in recent years, is also thought to be responsible for the development of FMS. ${ }^{2}$

Received: October 12, 2019 Accepted: December 22, 2019 Published online: February 07, 2020

Correspondence: Fatmanur Aybala Koçak, MD. Kırşehir Ahi Evran Üniversitesi Tıp Fakültesi, Fiziksel Tıp ve Rehabilitasyon Anabilim Dalı, 40100 Kırşehir, Türkiye. Tel: +90 386 - 2134515 e-mail: faybalarem@gmail.com

\section{Citation:}

Çetinkaya FN, Koçak FA, Kurt EE, Güçlü K, Tuncay F, Şaş S, et al. The Effects of Balneotherapy on Oxidant/Antioxidant Status in Patients With Fibromyalgia: An Observational Study. Arch Rheumatol 2020;35(4):506-514.

(02020 Turkish League Against Rheumatism. All rights reserved.

This is an open access article under the terms of the Creative Commons Attribution-NonCommercial License, which permits use, distribution and reproduction in any medium, provided the original work is properly cited and is not used for commercial purposes (http://creativecommons.org/licenses/by-nc/4.0/). 
In biologic systems, when the balance between free radicals and the antioxidants that detoxify them is disturbed, the negative effect of free radicals in the cells is defined as oxidative stress. ${ }^{3}$ Oxidative stress in FMS has been suggested to cause permanent damage to enzyme systems, including the use of cellular oxygen, causing oxygenation disturbance. ${ }^{4}$ Different oxidant substances can be measured individually in serum. However, it is impractical and leads to excessive time and material loss. Instead, total oxidant status (TOS) measurement methods, which collectively show the level of oxidants, have been developed. ${ }^{5}$ Total antioxidant status (TAS) is a parameter that reflects the total effect of antioxidants in all biologic samples, including antioxidants that have not yet been fully discovered. ${ }^{6}$ The percentage ratio of the total oxidant level to the total antioxidant level gives the oxidative stress index (OSI).

In some studies related to FMS, oxidative stress markers and antioxidant levels were examined and increased oxidant damage was detected. Neyal et al. ${ }^{7}$ found an increase in TOS and OSI levels in patients with FMS; Altindag and Celik $^{8}$ found a decrease in TAS levels and an increase in OSI levels. Oxidative stress was also associated with symptom severity in FMS. Oxidative damage due to free radicals, and decreased antioxidant capacity were found to be effective in the onset of the disease and the spread of pain. ${ }^{9,10}$

There is no single specific treatment for FMS. In addition to pharmacologic agents, exercise, cognitive/behavioral therapies, physical therapy methods, acupuncture, and balneotherapy are used alone or in combination.111 Balneotherapy is a therapy performed in a certain time interval and in a curing manner by using the serial, repeated bathing, packs, drinking, and inhalation applications of natural underground water-borne thermomineral waters, peloids, and gases. ${ }^{12}$ Water with a temperature above $20^{\circ} \mathrm{C}$ and a total mineral content exceeding $1 \mathrm{~g} / \mathrm{L}$ is called thermomineral water. ${ }^{13}$ These waters show their effects through mechanical, chemical, and thermal routes. ${ }^{14}$

Balneotherapy is the most preferred treatment for FMS after osteoarthritis in rheumatic and musculoskeletal diseases. Balneotherapy has a high level of evidence in almost all FMS treatment guidelines and has been reported by the European League Against Rheumatism (EULAR) as having level of evidence IIa. ${ }^{12}$ Many studies have shown positive effects of balneotherapy on FMS.15-17

Some studies on balneotherapy reported positive effects of balneotherapy on the antioxidant system in different rheumatic diseases such as rheumatoid arthritis (RA) and osteoarthritis (OA) ${ }^{18,19}$ However, to our knowledge, no studies in the literature have investigated the effect of balneotherapy on TAS, TOS, and OSI in patients with FMS. Therefore, in this study, we aimed to evaluate whether there was a difference between OSI, TAS, and TOS values between patients with FMS and healthy controls, and to show the effect of balneotherapy on clinical conditions such as pain, depression, and quality of life in patients with FMS and oxidative stress.

\section{PATIENTS AND METHODS}

This prospective observational study included 35 female patients (mean age $39.9 \pm 5.8$ years; range, 18 to 50 years) with FMS diagnosed according to the American College of Rheumatology (ACR) 2016 FMS diagnostic criteria ${ }^{20}$ who presented to the Physical Medicine and Rehabilitation outpatient clinic of Kırşehir Ahi Evran University Training and Research Hospital between February $1^{\text {st }}, 2019$ and April $1^{\text {st }}, 2019$ and 35 healthy females (mean age 37.9 \pm 6.6 years; range, 18 to 50 years) from the hospital staff (Figure 1). The study protocol was approved by the Kırşehir Ahi Evran University Ethics Committee. A written informed consent was obtained from each participant. The study was conducted in accordance with the principles of the Declaration of Helsinki. This study was registered in the Iranian Registry of Clinical Trials (IRCT), which is a primary registry in the World Health Organization Registry Network set. Trial ID of this study is 35965 and IRCT ID of this study is IRCT20180108038268N4.

It is known that fibromyalgia is seen mostly in the female sex. In this study, to achieve homogenization and to exclude etiologic factors that may be variable depending on sex, the patient and control groups were composed of females only. The exclusion criteria were as follows: presence of any systemic disease (hematologic, 
183 patients with fibromyalgia syndrome and 38 healthy controls were evaluated.

117 patients did not meet the inclusion criteria $(68$ patients having been under another treatment, 29 patients having systemic disease/hypovitaminosis/history of surgery, six patients in the period of pregnancy/lactation, 14 patients being smoker)

25 patients and three healthy controls did not want to join the study

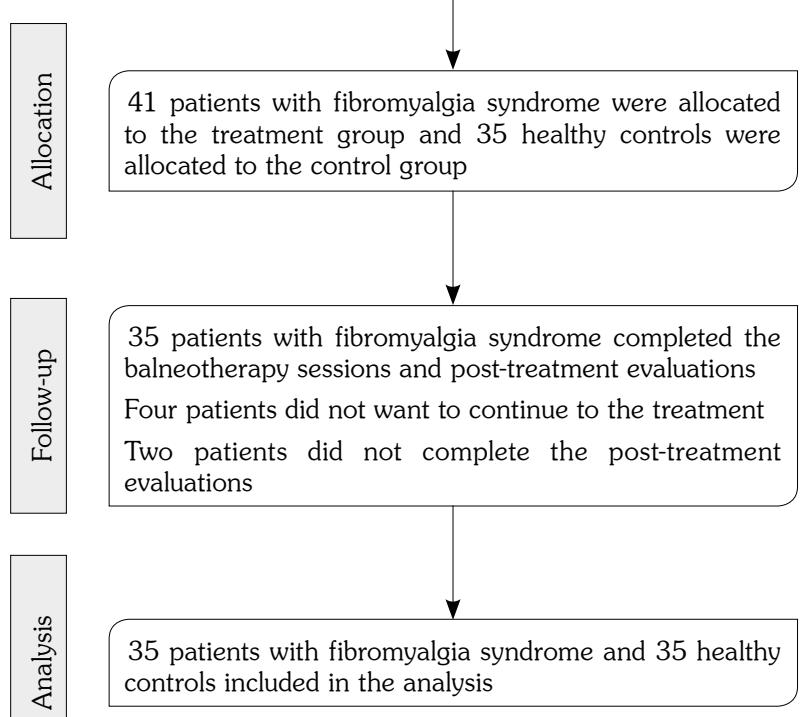

Figure 1. Flowchart of study.

endocrine, rheumatologic, renal, cardiovascular, gastrointestinal, respiratory disease); active infection; history of malignancy; surgery or major trauma in the last year; any treatment for FMS (e.g. balneotherapy, exercise, medical treatment) in the last three months; postmenopausal period, lactation, and pregnancy; smoking; and vitamin $\mathrm{D}$ deficiency.

The control group consisted of healthy females who met none of the exclusion criteria; did not have any disease and did not use any medication. Also, those with any kind of pain (headache, muscle pain, etc.), any intensity of pain (mild, moderate or severe), and any duration of pain (minutes, hours, etc.) in the last week were excluded.

Age, height, weight, body mass index, marital status, educational status, occupational status, medication used, and also the symptom duration (patient group) were questioned and recorded in both groups.
A Visual Analog Scale (VAS) was used to determine the pain level of the patients. ${ }^{21}$ In this scale, 0 indicates no pain and 10 is the worst possible pain. The pain of the control group was asked as the most severe pain that was experienced in any part of the body in the last month.

The Fibromyalgia Impact Questionnaire (FIQ) was used to evaluate functional status in patients with FMS. The scale, developed by Burchardt et al., ${ }^{22}$ is used to monitor the status and outcomes of patients. The Turkish reliability and validity study of the FIQ was done by Sarmer et al. ${ }^{23}$ The FIQ consists of 10 questions that assess physical functioning, work status, depression, anxiety, sleep, pain, stiffness, fatigue, and well-being. The total score ranges from 0 to 100 . Higher scores show more severe impairment.

The Short Form 36 (SF-36) was used to evaluate quality of life. The SF-36 form is a quality of life scale consisting of 36 questions. ${ }^{24}$ The Turkish reliability and validity study of the SF-36 was done by Koçyiğit et al. ${ }^{25}$ The questions include eight different statuses related to health: physical function, social function, physical role limitation, emotional role limitation, mental health, energyvitality, pain, and general health perception. Scores of questions for each status are scored between 0 (worst health condition) and 100 (best health condition).

The Beck Depression Inventory (BDI) developed by Beck et al. ${ }^{26}$ was used to evaluate the mood of the participants. The Turkish reliability and validity study of the BDI was done by Hisli. ${ }^{27}$ The scale consists of 21 questions and each question is scored between 0 and 3 . There are no depressive symptoms between 0 to 13 points, there are moderate depressive symptoms between 14 to 24 points, and severe depressive symptoms above 25 points. The highest possible score is 63 .

The VAS, SF-36, and BDI scores of the control group and FMS patients were recorded before treatment and a comparison was performed between the two groups. FMS patients additionally underwent the FIQ.

In addition, the scores of 'diffuse pain index' (0-19) and 'symptom severity scale' (0-12) of FMS patients were determined and the Fibromyalgia Severity Scale (FSS) score was obtained by adding 
these two scores. ${ }^{20}$ The FSS is used to assess disease severity during follow-up. The VAS, BDI, SF-36, FIQ, and FSS scores were calculated before and immediately after the completion of the treatment and the changes were evaluated.

Routine blood tests (hemogram, liver-kidneythyroid function tests, vitamin D concentration, erythrocyte sedimentation rate, and C-reactive protein) were performed in all patients and the control group. Patients without abnormalities in routine blood tests were included in the study. TAS, TOS, and OSI measurements were performed in the control group and in the preand post-treatment patient group.

Blood samples were collected from peripheral venous blood at the same time in the morning after eight hours of fasting. Sera were centrifuged at $1500 \mathrm{~g}$ for 10 minutes. Separated serum samples were kept in a $-80^{\circ} \mathrm{C}$ refrigerator until the day of analysis. The collected samples were analyzed using Rel Assay Diagnostics kits (Mega Tıp San. Tic. Ltd. Şti., Gaziantep, Türkiye) in the Biochemistry Laboratory of Kırşehir Ahi Evran University Training and Research Hospital.

Total antioxidant status was measured by a method developed by Erel, which is a fully automatic method that measures the total antioxidant capacity of the body against strong free radicals. ${ }^{28}$ The $\mathrm{Fe}^{+2}$ o-dianisidine complex forms the $\mathrm{OH}^{-}$radical through a Fenton-type reaction with hydrogen peroxide $\left(\mathrm{H}_{2} \mathrm{O}_{2}\right)$. These powerful reactive oxygen species are reduced and react with the colorless o-dianisidine molecule at low $\mathrm{pH}$ to form yellow-brown dianisidyl radicals. Dianisidyl radicals participate in advanced oxidation reactions and increase color formation. Antioxidants in the samples suppress these oxidation reactions and stop the formation of color. This reaction is measured spectrophotometrically on an automatic analyzer. The result is expressed in mmol Trolox equivalent (Eqv.)/L.

The TOS serum concentrations were measured using a fully automatic calorimetric method developed by Erel. ${ }^{5}$ The oxidants in the sample oxidize the ferrous ion-o-dianisidine complex to ferric ion, and glycerol in the sample accelerates this reaction three-fold. Ferric ions form a colored complex with xylenol orange in acidic media. The color intensity, which can be measured spectrophotometrically, is related to the total amount of oxidant molecules in the sample. The result is expressed in $\mu \mathrm{mol}$ $\mathrm{H}_{2} \mathrm{O}_{2}$ Eqv./L.

The OSI, which is an indicator of oxidative stress, was calculated by measuring TOS and TAS automatically using the following formula: OSI $=\left[\left(\mathrm{TOS}, \mu \mathrm{mol} \mathrm{H}_{2} \mathrm{O}_{2}\right.\right.$ Eqv./L)/(TAS, $\mu \mathrm{mol}$ $\mathrm{H}_{2} \mathrm{O}_{2}$ Eqv./L) $\left.\times 100\right]$. During the calculations, TAS measurement values were converted from $\mathrm{mmol}$ Trolox Eqv./L to $\mu \mathrm{mol}$ Trolox Eqv./L.

Blood samples (after completion of the treatment) were collected one day after the last balneotherapy session, in the morning hours after eight hours of fasting.

Balneotherapy treatment was given to FMS patients in Kurşehir Terme Thermal Springs, which operates within the Kırşehir Ahi Evran University Training and Research Hospital Physical Medicine and Rehabilitation Department. The total mineralization content of the spa water with a temperature of $42 \pm 1^{\circ} \mathrm{C}$ was $98.3 \mathrm{mg} / \mathrm{L}$ sulfate, $556 \mathrm{mg} / \mathrm{L}$ bicarbonate, $186.7 \mathrm{mg} / \mathrm{L}$ sodium, $34.5 \mathrm{mg} / \mathrm{L}$ magnesium, $226 \mathrm{mg} / \mathrm{L}$ calcium, $232 \mathrm{mg} / \mathrm{L}$ chloride, $2.6 \mathrm{mg} / \mathrm{L}$ fluoride, and $58.43 \mathrm{mg} / \mathrm{L}$ silicate acid. Balneotherapy was given to the patients in the form of a whole body bath at 09:00 AM for 20 minutes. During the balneotherapy session, the patients did not do any activity (walking, aquatic exercise etc.); they just sat down and received full body immersion in the thermomineral water pool. The patients received a total of 15 sessions of treatment for five days a week for three weeks. Daily routine activities were not changed. No other pharmacologic or non-pharmacologic treatment was applied to the patients.

\section{Statistical analysis}

The IBM SPSS version 20.0 software (IBM Corp., Armonk, NY, USA) was used for statistical analysis. Descriptive statistics are shown as mean \pm standard deviation and percentage. The chi-square test was used to compare qualitative data. The Kolmogorov-Smirnov test was used to determine whether the distribution of the variables was suitable for normal distribution. The independent sample t-test was used for the comparison of independent data matching 


\begin{tabular}{|c|c|c|c|}
\hline & Patient group $(\mathrm{n}=35)$ & Control group $(\mathrm{n}=35)$ & \\
\hline & Mean \pm SD & Mean \pm SD & $p^{*}$ \\
\hline Age (year) & $39.9 \pm 5.8$ & $37.9 \pm 6.6$ & 0.189 \\
\hline Body weight $(\mathrm{kg})$ & $67.9 \pm 9.5$ & $70.7 \pm 8.2$ & 0.205 \\
\hline Height (meter) & $1.6 \pm 0.1$ & $1.7 \pm 0.1$ & 0.190 \\
\hline Body mass index $\left(\mathrm{kg} / \mathrm{m}^{2}\right)$ & $25.3 \pm 2.7$ & $25.8 \pm 2.3$ & 0.450 \\
\hline
\end{tabular}

normal distribution, and the Mann-Whitney $\mathrm{U}$ test was used for the comparison of independent data not matching normal distribution. In repeated measurements, the paired-sample t-test was used for the comparison of data matching normal distribution, and the Wilcoxon test was to compare data that did not match normal distribution. A $p$ value $<0.05$ was accepted as statistically significant. The G*Power version 3.1.9.2 software (Heinrich-Heine Universität Düsseldorf, Düsseldorf, Germany) was used to determine the sample size of the study. Having scanned the current literature, based on the mean and standard deviation of OSI levels in Altindag and Celik study, ${ }^{8}$ it was concluded that a minimum of 32 persons should be recruited to each group to achieve the effect size $\mathrm{d}=0.919$ between the groups with $95 \%$ power and a $5 \%$ error margin.

\section{RESULTS}

The demographic characteristics of the participants such as age, body weight, and height are shown in Table 1. There was no statistically significant difference between the two groups in terms of demographic characteristics. There was no statistically significant difference between the two groups in terms of marital status, educational status, and occupation either ( $p>0.05$ ). The mean duration of disease in patients with FMS was $5.9 \pm 5.0$ years.

The pre-treatment VAS, BDI, and SF-36 scales of the control group and FMS patients were evaluated. The VAS and BDI scores were higher in the patients compared with the control group, whereas the SF-36 scores were significantly lower. The findings are summarized in Table 2.

\begin{tabular}{|c|c|c|c|}
\hline & Patient group & Control group & \\
\hline & Mean $\pm S D$ & Mean \pm SD & $p^{*}$ \\
\hline Visual analog scale & $8.1 \pm 1.2$ & $2.6 \pm 1.4^{* * *}$ & $<0.001$ \\
\hline Beck Depression Inventory & $19.9 \pm 6.7$ & $6.3 \pm 3.2$ & $<0.001$ \\
\hline SF-36 physical function & $62.7 \pm 11.8$ & $74.7 \pm 14.5$ & $<0.001$ \\
\hline SF-36 physical role limitation & $1.4 \pm 8.5$ & $72.9 \pm 27.4$ & $<0.001$ \\
\hline SF-36 pain & $30.4 \pm 15.0$ & $75.9 \pm 13.5$ & $<0.001$ \\
\hline SF-36 social function & $43.2 \pm 16.2$ & $71.1 \pm 17.2$ & $<0.001$ \\
\hline SF-36 mental health & $46.1 \pm 11.0$ & $74.0 \pm 14.8$ & $<0.001$ \\
\hline SF-36 emotional role limitation & $8.6 \pm 20.3$ & $85.7 \pm 20.3$ & $<0.001$ \\
\hline SF-36 energy-vitality & $26.9 \pm 9.2$ & $67.7 \pm 12.7$ & $<0.001$ \\
\hline SF-36 general health perception & $32.1 \pm 16.8$ & $64.4 \pm 10.2$ & $<0.001$ \\
\hline
\end{tabular}


Table 3. Comparison of pre-treatment laboratory parameters of patients with fibromyalgia syndrome and control group

\begin{tabular}{lcccc}
\hline & Patient group & & Control group & \\
\cline { 2 - 2 } & Mean \pm SD & & Mean \pm SD & $p^{*}$ \\
\hline TAS $\dagger$ & $1.2 \pm 0.1$ & & $1.2 \pm 0.9$ & 0.114 \\
TOS $\neq$ & $10.5 \pm 3.6$ & & $7.1 \pm 2.2$ & $<0.001$ \\
OSI & $0.9 \pm 0.3$ & & $0.6 \pm 0.2$ & $<0.001$ \\
\hline
\end{tabular}

SD: Standard deviation; TAS: Total antioxidant status; TOS: Total oxidant status; OSI: Oxidative stress index; * $p<0.05$ is statistically significant; $\dagger$ TAS unit: $\mathrm{mmol}$ Trolox equivalent/L; $\neq$ TOS unit: $\mu \mathrm{mol}$ hydrogen peroxide $\left(\mathrm{H}_{2} \mathrm{O}_{2}\right)$ equivalent/L.

The pre-treatment TAS, TOS, and OSI values of FMS patients were compared with the control group. There was no significant difference in TAS values between the controls and FMS patients before balneotherapy; TOS and OSI values were significantly higher in FMS patients (Table 3).

The clinical and laboratory evaluations of the patients were repeated after balneotherapy treatment. Although a statistically significant decrease in TOS and OSI values was found in laboratory evaluations, there was no significant change in TAS values. In the evaluation of pain severity, the mean VAS values before and after treatment were 8.11 and 5.42 , respectively; a statistically significant decrease was observed $(p<0.001)$. SF-36 and BDI scores improved significantly after balneotherapy. Significant improvements were found in the FSS and FIQ; the changes in all parameters are shown in Table 4.

\section{DISCUSSION}

The aim of this study was to compare the oxidant-antioxidant balance in patients with FMS and healthy controls, and to evaluate the effect of balneotherapy on oxidative stress. To our knowledge, this is the first study to evaluate the effect of balneotherapy on TAS, TOS, and OSI in patients with FMS. The results of this study indicate that FMS has an increased tendency towards oxidant stress compared with healthy individuals and balneotherapy has antioxidant activity and it decreases oxidant activity and changes the balance in the direction of reduction in oxidative stress.

Table 4. Comparison of pre-treatment and post-treatment clinical and laboratory parameters of patients with fibromyalgia syndrome

\begin{tabular}{lcccc}
\hline & Pre-treatment & & Post-treatment \\
\cline { 2 - 2 } & Mean \pm SD & & Mean \pm SD & $p^{*}$ \\
\hline TAS† & $1.2 \pm 0.1$ & & $1.2 \pm 0.1$ & 0.538 \\
TOS $\neq$ & $10.5 \pm 3.6$ & & $7.4 \pm 2.6$ & $<0.001$ \\
OSI & $0.9 \pm 0.3$ & & $0.6 \pm 0.2$ & $<0.001$ \\
Visual analog scale & $8.1 \pm 1.2$ & & $5.4 \pm 1.9$ & $<0.001$ \\
FIQ & $61.9 \pm 10.5$ & & $41.1 \pm 14.8$ & $<0.001$ \\
Beck Depression Inventory & $19.9 \pm 6.7$ & & $10.7 \pm 5.1$ & $<0.001$ \\
SF-36 physical function & $62.7 \pm 11.8$ & & $74.2 \pm 10.3$ & $<0.001$ \\
SF-36 physical role limitation & $1.4 \pm 8.5$ & & $15.0 \pm 32.8$ & 0.017 \\
SF-36 pain & $30.4 \pm 15.0$ & & $52.6 \pm 15.4$ & $<0.001$ \\
SF-36 social function & $43.2 \pm 16.2$ & & $53.6 \pm 15.6$ & $<0.001$ \\
SF-36 mental health & $46.1 \pm 11.0$ & & $59.7 \pm 9.8$ & $<0.001$ \\
SF-36 emotional role limitation & $8.6 \pm 20.3$ & & $39.0 \pm 37.4$ & $<0.001$ \\
SF-36 energy-vitality & $26.9 \pm 9.2$ & & $43.4 \pm 13.9$ & $<0.001$ \\
SF-36 general health perception & $32.1 \pm 16.8$ & $49.6 \pm 14.7$ & $<0.001$ \\
FSS & $22.3 \pm 3.9$ & $13.7 \pm 4.7$ & $<0.001$ \\
\hline
\end{tabular}

SD: Standard deviation; TAS: Total antioxidant status; TOS: Total oxidant status; OSI: Oxidative stress index; FIQ: Fibromyalgia Impact Questionnaire; SF-36: Short Form-36; FSS: Fibromyalgia Severity Scale; ${ }^{*} \mathrm{p}<0.05$ is statistically significant; † TAS Unit: mmol Trolox equivalent/L, $\neq$ TOS Unit: $\mu$ mol hydrogen peroxide $\left(\mathrm{H}_{2} \mathrm{O}_{2}\right)$ equivalent/L. 
Oxidative stress, which has been shown in the etiology of $\mathrm{RA}, \mathrm{OA}$, and chronic fatigue syndrome in recent years, is thought to play a role in the etiology of FMS. ${ }^{18,19,29,30}$ Oxidative stress is thought to contribute to the alteration of peripheral and central sensitization, and nociception and hyperalgesia. ${ }^{31}$

Bagis et al. ${ }^{9}$ compared 85 patients with FMS and 80 healthy controls and found high malondialdehyde (MDA) levels, a lipid peroxidation product, and a significant decrease in superoxide dismutase (SOD) levels, which plays an enzymatic role in the antioxidant system in the patient group. In a study using MDA and ischemiamodified albumin concentrations as indicators of oxidative stress, and SOD concentrations as an indicator of antioxidants, 38 healthy individuals were compared with 59 patients with FMS and MDA was significantly higher in the FMS group than in the healthy group. Although ischemiamodified albumin was higher than in the control group, no significant results were obtained. SOD levels were found to be higher in the fibromyalgia group but no significant elevation was observed. ${ }^{32}$ Neyal et al. ${ }^{7}$ showed low plasma nitrite levels and TAS, and increased TOS and OSI levels in patients with FMS. Similarly, some other studies reported increased oxidant activity and decreased antioxidant activity in patients with FMS. ${ }^{8,33}$ Bozkurt et al. ${ }^{34}$ reported that TOS and OSI values were significantly higher in the FMS group compared with a healthy group; TAS levels were lower in the FMS group but it was not statistically significant. In the present study, TOS and OSI were found to be significantly higher in patients with FMS than in the control group. TAS values were higher in the patient group but not significantly. In a system based on equilibrium, it is thought that high TAS values are formed in response to the increased oxidant status. When the studies in the literature are examined in general, the predominant view is increased activation in the oxidant system. According to the data obtained from the present study, we can say that FMS might have an increased tendency towards oxidant stress compared with healthy individuals.

The FMS treatment with a complex etiopathogenesis is difficult for physicians and requires a multidisciplinary approach involving a combination of appropriate treatment modalities.
Balneotherapy has been used for many years in the treatment of rheumatic diseases such as OA, $\mathrm{RA}$, and painful conditions of the musculoskeletal system. It has been suggested to be one of the most promising therapies among the nonpharmacologic methods that have significant effects on pain and symptoms in patients with FMS. 12,35,36 Many studies have been conducted to evaluate the unclear effectiveness of spa treatment on the oxidant-antioxidant system and positive effects have been reported. In a study of patients with OA, a decrease in MDA concentration and catalase activity was shown with sulfur baths. ${ }^{37}$ In another study, SOD levels were significantly decreased in patients with OA after sulfur baths. ${ }^{18}$ Bender et al. ${ }^{38}$ compared thermomineral water with tap water in patients with chronic low back pain and levels of oxidative stress markers were found to be significantly decreased in patients treated with thermomineral water.

Balneotherapy is also thought to produce antioxidant and anti-inflammatory effects by reducing the free radical scavenging effects. ${ }^{39}$ In the present study, there was no significant change in TAS values after the spa; however, there was a statistically significant decrease in TOS and OSI. This may show that balneotherapy has antioxidant activity and it decreases oxidant activity and changes the balance in the direction of reduction in oxidative stress.

Balneotherapy is also a non-pharmacologic treatment effective on the improvement of FMS symptoms and functions. Many studies in the literature have reported positive effects of balneotherapy on pain, functional status, number of tender points, depressive mood, fatigue, and sleep quality..$^{15-17,40,41}$ In the present study, significant improvements were found in pain levels, depressive mood levels, quality of life, functional status, and FIQ values, which were included in the 2016 ACR criteria and used in the follow-up of disease severity after balneotherapy. To our knowledge, no studies have evaluated the effect of balneotherapy on FSS in the literature. This is the first study on this subject. All these results may show that balneotherapy has positive effects on the symptoms, disease severity, quality of life, and functional status of patients with FMS, in addition to the effects of oxidative stress. 
Limitations of this study included the evaluation of only the short-term efficacy and the absence of long-term outcomes. Studies including long-term results are needed to assess the sustainability of treatment effects. Another limitation was the lack of a control group consisting of FMS patients with no treatment. However, it was ethically not appropriate to leave a group completely untreated in a disease where widespread pain was the main symptom. Furthermore, the use of a single treatment method was another limitation. Randomized controlled trials may be recommended to compare the efficacy of balneotherapy with other treatment modalities.

In conclusion, the results of this study showed increased oxidant status and presence of oxidative stress in patients with FMS. Although the elevation in TAS levels was not significant, it was thought that it was caused by a reactive increase against the increased oxidant status. The improvement of TOS and OSI levels in patients with FMS after balneotherapy supports the antioxidant efficacy of balneotherapy. In addition, significant improvements were achieved with balneotherapy in FIQ and FSS, which are indicators of disease severity, showing that it is an effective treatment method. Significant improvements in the VAS, BDI, and SF-36 parameters of patients after balneotherapy indicate that it has a significant effect on disease symptoms, quality of life, and functions, as well as biochemical effects.

\section{Declaration of conflicting interests}

The authors declared no conflicts of interest with respect to the authorship and/or publication of this article.

\section{Funding}

This study was funded by Kırşehir Ahi Evran University Scientific Research Project Unit (Grant number: TIP. A4.18.001).

\section{REFERENCES}

1. Macfarlane GJ, Kronisch C, Dean LE, Atzeni F, Häuser W, Fluß E, et al. EULAR revised recommendations for the management of fibromyalgia. Ann Rheum Dis 2017;76:318-28.
2. Ozgocmen S, Ozyurt H, Sogut S, Akyol O. Current concepts in the pathophysiology of fibromyalgia: the potential role of oxidative stress and nitric oxide. Rheumatol Int 2006;26:585-97.

3. Özcan O, Erdal H, Çakırca G, Yönden Z. Oxidative stress and its impacts on intracellular lipids, proteins and DNA. J Clin Exp Invest 2015;6:331-6.

4. Ali M. The cause of fibromyalgia: the respiratoryto-fermentative shift (the DysOx State) in ATP production. J Integr Med 2003;8:135-40.

5. Erel O. A new automated colorimetric method for measuring total oxidant status. Clin Biochem 2005;38:1103-11.

6. Erel O. A novel automated direct measurement method for total antioxidant capacity using a new generation, more stable ABTS radical cation. Clin Biochem 2004;37:277-85.

7. Neyal M, Yimenicioglu F, Aydeniz A, Taskin A, Saglam S, Cekmen M, et al. Plasma nitrite levels, total antioxidant status, total oxidant status, and oxidative stress index in patients with tension-type headache and fibromyalgia. Clin Neurol Neurosurg 2013;115:736-40.

8. Altindag $\mathrm{O}$, Celik $\mathrm{H}$. Total antioxidant capacity and the severity of the pain in patients with fibromyalgia. Redox Rep 2006;11:131-5.

9. Bagis S, Tamer L, Sahin G, Bilgin R, Guler H, Ercan $\mathrm{B}$, et al. Free radicals and antioxidants in primary fibromyalgia: an oxidative stress disorder? Rheumatol Int 2005;25:188-90.

10. Ozgocmen S, Ozyurt H, Sogut S, Akyol O, Ardicoglu O, Yildizhan $\mathrm{H}$. Antioxidant status, lipid peroxidation and nitric oxide in fibromyalgia: etiologic and therapeutic concerns. Rheumatol Int 2006;26:598-603.

11. Sevimli D, Kozanoglu E, Guzel R, Doganay A. The effects of aquatic, isometric strength-stretching and aerobic exercise on physical and psychological parameters of female patients with fibromyalgia syndrome. J Phys Ther Sci 2015;27:1781-6.

12. Özgen M. Spa Therapy in Fibromyalgia. Turkiye Klinikleri J PM\&R-Special Topics 2018;11:37-42.

13. Armagan O. Overview of health resort and balneotherapy treatment, past and present. Turkiye Klinikleri J PM\&R-Special Topics 2018;11:1-9.

14. Mooventhan A, Nivethitha L. Scientific evidencebased effects of hydrotherapy on various systems of the body. N Am J Med Sci 2014;6:199-209.

15. Evcik D, Kizilay B, Gökçen E. The effects of balneotherapy on fibromyalgia patients. Rheumatol Int 2002;22:56-9.

16. Fraioli A, Grassi M, Mennuni G, Geraci A, Petraccia $\mathrm{L}$, Fontana $\mathrm{M}$, et al. Clinical researches on the efficacy of spa therapy in fibromyalgia. A systematic review. Ann Ist Super Sanita 2013;49:219-29.

17. Naumann J, Sadaghiani C. Therapeutic benefit of balneotherapy and hydrotherapy in the management of fibromyalgia syndrome: a qualitative systematic 
review and meta-analysis of randomized controlled trials. Arthritis Res Ther 2014;16:R141.

18. Ekmekcioglu C, Strauss-Blasche G, Holzer F, Marktl W. Effect of sulfur baths on antioxidative defense systems, peroxide concentrations and lipid levels in patients with degenerative osteoarthritis. Forsch Komplementarmed Klass Naturheilkd 2002;9:216-20.

19. Karagülle M, Kardeş S, Karagülle O, Dişçi R, Avc1 A, Durak İ, et al. Effect of spa therapy with saline balneotherapy on oxidant/antioxidant status in patients with rheumatoid arthritis: a single-blind randomized controlled trial. Int J Biometeorol 2017;61:169-80.

20. Wolfe F, Clauw DJ, Fitzcharles MA, Goldenberg DL, Häuser W, Katz RL, et al. 2016 Revisions to the 2010/2011 fibromyalgia diagnostic criteria. Semin Arthritis Rheum 2016;46:319-29.

21. Freyd, M. The graphic rating scale. Journal of Educational Psychology 1923;14:83-102.

22. Burckhardt CS, Clark SR, Bennett RM. The fibromyalgia impact questionnaire: development and validation. J Rheumatol 1991;18:728-33.

23. Sarmer S, Ergin S, Yavuzer G. The validity and reliability of the Turkish version of the Fibromyalgia Impact Questionnaire. Rheumatol Int 2000;20:9-12.

24. Ware JE Jr, Sherbourne CD. The MOS 36-item shortform health survey (SF-36). I. Conceptual framework and item selection. Med Care 1992;30:473-83.

25. Koçyiğit H, Aydemir Ö, Fişek G, Ölmez N, Memiş AK. Form-36 (KF-36)'nın Türkçe versiyonunun güvenilirliği ve geçerliliği. İlaç ve Tedavi Dergisi 1999;12:102-6.

26. Beck AT, Ward CH, Mendelson M, Mock J, Erbaugh J. An inventory for measuring depression. Arch Gen Psychiatry 1961;4:561-71.

27. Hisli N. Beck Depresyon Envanterinin Geçerliği Üzerine Bir Çalışma. Psikoloji Dergisi 1988;22;11826.

28. Erel O. A novel automated method to measure total antioxidant response against potent free radical reactions. Clin Biochem 2004;37:112-9.

29. Altay MA, Ertürk C, Bilge A, Yaptı M, Levent A, Aksoy N. Evaluation of prolidase activity and oxidative status in patients with knee osteoarthritis: relationships with radiographic severity and clinical parameters. Rheumatol Int 2015;35:1725-31.

30. Romano GF, Tomassi S, Russell A, Mondelli V, Pariante CM. Fibromyalgia and chronic fatigue: the underlying biology and related theoretical issues. Adv Psychosom Med 2015;34:61-77.

31. Wang ZQ, Porreca F, Cuzzocrea S, Galen K, Lightfoot $\mathrm{R}$, Masini $\mathrm{E}$, et al. A newly identified role for superoxide in inflammatory pain. J Pharmacol Exp Ther 2004;309:869-78.

32. Toker A, Kucuksen S, Kucuk A, Cicekler H. Serum ischemia-modified albumin and malondialdehyde levels and superoxide dismutase activity in patients with fibromyalgia. Clin Lab 2014;60:1609-15.

33. Altindag O, Gur A, Calgan N, Soran N, Celik H, Selek S. Paraoxonase and arylesterase activities in fibromyalgia. Redox Rep 2007;12:134-8.

34. Bozkurt M, Caglayan M, Oktayoglu P, Em S, Batmaz I, Sariyildiz MA, et al. Serum prolidase enzyme activity and oxidative status in patients with fibromyalgia. Redox Rep 2014;19:148-53.

35. Nüesch E, Häuser W, Bernardy K, Barth J, Jüni P. Comparative efficacy of pharmacological and non-pharmacological interventions in fibromyalgia syndrome: network meta-analysis. Ann Rheum Dis 2013;72:955-62.

36. Terhorst L, Schneider MJ, Kim KH, Goozdich LM, Stilley CS. Complementary and alternative medicine in the treatment of pain in fibromyalgia: a systematic review of randomized controlled trials. J Manipulative Physiol Ther 2011;34:483-96.

37. Jokic A, Sremcevic N, Karagülle Z, Pekmezovic T, Davidovic V. Oxidative stress, hemoglobin content, superoxide dismutase and catalase activity influenced by sulphur baths and mud packs in patients with osteoarthritis. Vojnosanit Pregl 2010;67:573-8.

38. Bender T, Bariska J, Vághy R, Gomez R, Imre Kovács. Effect of balneotherapy on the antioxidant system--a controlled pilot study. Arch Med Res 2007;38:86-9.

39. Gálvez I, Torres-Piles S, Ortega-Rincón E. Balneotherapy, immune system, and stress response: A hormetic strategy? Int J Mol Sci 2018;19(6). pii: E1687.

40. Altan L, Bingöl U, Aykaç M, Koç Z, Yurtkuran M. Investigation of the effects of pool-based exercise on fibromyalgia syndrome. Rheumatol Int 2004;24:272-7.

41. Kurt EE, Koçak FA, Erdem HR, Tuncay F, Kelez F. Which Non-Pharmacological Treatment is More Effective on Clinical Parameters in Patients With Fibromyalgia: Balneotherapy or Aerobic Exercise? Arch Rheumatol 2016;31:162-9. 